\title{
DROUGHT RESPONSIVE GENE MECHANISMS DURING THE INITIAL GROWTH PHASE IN MAIZE (ZEA MAYS L.)
}

\author{
IBRAR, M. ${ }^{1,2}$ - MALIK, S. I. ${ }^{1}$ - SHAH, M. K. N. ${ }^{1}$ - Ul HASSAN, F. ${ }^{3}$ \\ ${ }^{I}$ Department of Plant Breeding and Genetics, PMAS Arid Agriculture University, Rawalpindi, \\ Pakistan \\ ${ }^{2}$ Agriculture Research Institute, Sariab, Government of Balochistan, Quetta, Pakistan \\ ${ }^{3}$ Department of Agronomy, PMAS Arid Agriculture University, Rawalpindi, Pakistan \\ *Corresponding author \\ e-mail:abrarquetta@gmail.com
}

(Received 12 $2^{\text {th }}$ Sep 2021; accepted $23^{\text {rd }}$ Nov 2021)

\begin{abstract}
Climate change, global warming and increasing drought are critical issues for the world and particularly for developing countries. Drought severely affects maize and causes heavy yield losses. Improving maize genetically against drought stress is an integral strategy to overcome this problem. Identifying drought responsive genes and their expression profiling is helpful for this purpose. Droughtresponsive genes from phylogenetically related crops were hunted for the maize genome. Candidate maize genes with unknown functions were analyzed. Out of 9 selected candidate genes, two genes GSNOR and $C D P K 7$ were found differentially regulating under drought stress. They displayed down regulation in roots, whereas, in leaves both genes were up-regulated under drought conditions. Apparently, under stress conditions signaling of $\mathrm{Ca}^{+2}$ and $\mathrm{NO}$ initiated in roots, then moved to stem and leaves shifting its load to aerial plant parts to overcome water deficit conditions. Results suggest that GSNOR and CDPK7 have potential to enhance maize plants' ability to resist water deficit conditions. GSNOR and CDPK7 enable maize plants to encounter drought stress through nitrosylation and phosphorylation of their target proteins. Thus, they modify downstream gene expression, protein functions and activity. Identified genes may prove useful in improving maize plants to face drought stress conditions.

Keywords: drought responsive genes, phosphorylation, gene expression profiling, S-nitrosoglutathione reductase (GSNOR), calcium dependent protein kinases (CDPK7)
\end{abstract}

\section{Introduction}

The developing countries of South East Asia face the challenge of water scarcity (Greve et al., 2018). Unfortunately, Pakistan also confronted by agricultural and domestic water shortage. Pakistan is one of the countries which are facing water scarcity and the situation is expected to get worse in the forthcoming years (Khoso et al., 2015). Scarcity of water inflicts a quite significant and heavy economic loss to the agricultural crops and climatic changes taking place globally are predicted to make the problem worse (Battisti and Naylor, 2009; Marris, 2008). Drought and salinity are the two factors that cause about $50 \%$ reduction in yields of main crops throughout the world (Majeed and Muhammad, 2019). The drought problem is quite ubiquitous, alarming and it may have a catastrophic effect on economy of a country relying on agriculture produce (Ali et al., 2017).

In case of maize, water deficient conditions influence the crop physiology thus inflicting heavy production losses. Due to water deficiency at initial reproductive growth stages, defoliation takes place in maize crop which ultimately reduces the grain yield (Jaleel et al., 2009; Monneveux et al., 2006). Water deficiency has negative impacts during anthesis, pollination, anthesis-silking stage and formation of the grains in corn (Aslam et al., 2013). An unfortunate fact found by the plant breeders was that 
tolerance against drought in maize is quite complex feature, thus it becomes difficult for them to make a selection, screening and breeding for the suitable features (Luo et al., 2019). One of the possible solutions to cope with drought conditions is development of drought tolerant cultivars (Nuccio et al., 2015). However, lack of sufficient genetic resources available in maize is the reason for slow progress towards development of drought tolerant cultivars (Mugo et al., 2005). Several studies have employed the forward genetic approaches like proteome analysis, quantitative real-time PCR and field evaluation for identifying differential expression of candidate genes under drought stress in maize (Wang et al., 2019). A large number of genes are conserved across the plant species which have similar structure and function. These conserved genes are searched in other phylogenetically related plant species (Alexandrov et al., 2009). Identification of genes which are responsive against water deficit conditions can be a useful tool to understand biological systems adapted by the plants against drought stress (Langridge and Reynolds, 2015). Several molecular markers have been developed and genes identified on the basis of differential expression of candidate genes and these findings are being applied to maize improvement programmes focused on drought tolerance (Mao et al., 2015). Identification of genes which are responsive against water deficit conditions can be a useful tool to understand biological systems adapted by the plants against drought stress (Langridge and Reynolds, 2015).

Several genes are reported to play their role under drought stress conditions. For instance, Liang et al. (2011) stated that $R A B 18$ showed its response against water deficit conditions in the presence of ABA as stimulus via ABA-dependent pathway. SNF1related protein kinase 2 proteins $(S n R K s)$ play major function in phosphorylation process of AREB1 through ABA dependent pathway (Yoshida et al., 2010). Similarly, NRGA1 from Arabidopsis acts as pyruvate carrier for mitochondria and it negatively controls guard cell signaling, induced by ABA (Li et al., 2014). When $n r g a$ loss-offunction mutants were tested, plants showed high sensitivity in the presence of ABA in perspective of stomatal movements, demonstrated an intensified tolerance against drought stress. In contrast to this, over-expressing lines for NRGAI depicted contrasting stomatal responses, decreased tolerance against drought and activation for anion channels. Another gene AtCIPKl depicted its key importance in stress induced pathways. AtCIPK1 combine both ABA-dependent as well as ABA-independent features for signaling against abiotic stresses (D'Angelo et al., 2006). It was found that AtCIPK23 initiates channel for potassium ions, controls transpiration process in leaves and absorption of potassium ions in Arabidopsis while interacting along with CBL9 and CBL1 (Cheong et al., 2007). Another stress responsive gene CIPK found in Pisum sativum showed up-regulation in coordination with $C B L$ and gave relative response against biotic and abiotic stresses, SA and calcium (Mahajan et al., 2006). For various environmental signaling, calcium ions play a central part as secondary messenger intracellularly. Calcineurin B-like proteins, as well as their targeted proteins depicted mediatory role in signaling network against various environmental stresses faced by the plants (Chen et al., 2011). Nakashima et al. (2007) implied that a drought responsive gene in rice NAC6 showed its expression in biotic and abiotic stress conditions. If OsNAC6 is used in combination with stress inducible promoters, this technique can be beneficial in molecular breeding against stress tolerance. Transgenic tomato plants were developed by inserting yeast TPS1 gene. These transgenic plants showed enhanced chlorophyll as well as starch contents and as a result their tolerance against drought, oxidative stress and salt stress was increased (Cortina and Culianez-Macia, 2005). 
GSNOR plays pivotal role under various stresses. The gene plays vital part in maintaining homeostatic balance of nitric oxide and thus regulating the process of nitrosylation. S-nitrosoglutathione reductase (GSNOR), catabolizes and splits GSNO into oxidized glutathione (GSSG) and ammonia. As a result, GSNOR regulates and maintains GSNO levels in various biotic as well as abiotic stresses (Leterrier et al., 2011). Moreover, GSNO is able to perform transnitrosylation, during which NO functional group is shifted from $S$-nitroshthiol to any cysteine thiol group of a particular target protein. GSNO is studied for S-nitrosylation of various proteins as GSNO is associated with responses of plants which are exposed to various types of stresses (Chaki et al., 2009).

Nitrosylation and phosphorylation are analogous in cellular biology, as both change the expression of their target genes and alter protein activity as well as function. As GSNOR regulates the process of nitrosylation, similarly CDPKs perform phosphorylation reactions. Both GSNOR and CDPKS regulate the process of nitrosylation and phosphorylation respectively, thus affecting downstream events taking place in the cytosol, for the purpose of drought management. Several biochemical reactions in plants are closely linked with phosphorylation of proteins (Luo et al., 2018). Calcium ions play a significant role in transmitting messages for several signal transduction routes among such signal transduction pathways (Asano et al., 2012). In response to a particular environmental stimulus (e.g., abiotic stress) concentration of $\mathrm{Ca}^{2+}$ is enhanced temporarily and this elevation is identified by many $\mathrm{Ca}^{2+}$ sensors or Ca-binding proteins (Rudd and Franklin-Tong, 2001). The elevation of $\mathrm{Ca}^{2+}$ introduces modified protein phosphorylation as well as changes in the gene expression patterns as downstream effects (Tuteja and Mahajan, 2007).

Identification and characterization of drought responsive genes is one important step in this direction. The main objective of this study was to identify novel drought responsive genes in maize and conducting their expression profiling. As we know genes are conserved among all species, therefore it was hypothesized that drought responsive genes, reported in crops which are phylogenetically related to maize, would be present in maize genome as well. Therefore, such genes were hunted in maize genome and their gene expression profiling was carried out under drought stress conditions. The main objective of this research was to identify drought responsive genes in maize genome and to perform their expression profiling.

\section{Materials and methods}

\section{Plant materials and growth conditions}

The research was carried out in PMAS Arid Agriculture University Rawalpindi, Pakistan. The seedlings of maize genotype Soan-3 were grown in glasshouse $(32 \pm 4$ $\left.{ }^{\circ} \mathrm{C}\right)$ to examine their drought tolerance at early development stage. Soan-3 cultivar was taken as Reference Genome. The selected genotype was grown in potting media with the composition of sand, soil and farm yard manure (FYM) at 1:2:1 ratio, respectively. Size of all pots was $250 \mathrm{ml}$.

\section{Drought stress treatment}

The maize seedlings were grown in pots and watered regularly up to 14 days. Twoweeks old maize seedlings were maintained under similar growth conditions and subjected 
to drought stress by withholding water for two days. After withholding water for two days i.e., for $48 \mathrm{~h}$, then the time points for six drought stress treatments were counted. The drought stress treatments were given at $0 \mathrm{~h}, 6 \mathrm{~h}, 12 \mathrm{~h}, 24 \mathrm{~h}, 30 \mathrm{~h}$ and finally $10 \mathrm{~h}$ after providing recovery irrigation. These six time points of collecting samples were based on observations of gradual increase in symptoms of drought stress on maize seedlings. BBCH growth stage of the maize seedlings was V3. After two weeks of seed germination, it was V3 stage when drought stress treatments were given and samples were collected. Four plants represented one treatment of drought stress for each time course.

\section{Selection of drought responsive genes}

The drought responsive genes were searched in crops which are phylogenetically related to maize. Then their orthologues were searched in maize genome with an assumption that their homologous sequences may be present in maize genome as well. Maize genome sequence databases (Mittal et al., 2017) and available online tools were used (Jiao et al., 2017). The decision of selecting identical sequences was taken on protein homology as proteins are functional entities rather than nucleotides. Thus, several amino acids' sequences were used through Basic Local Alignment Search Tool (BLAST) (Pearson, 2013). Among all the searched genes only those were chosen as our candidate genes which depicted more than $70 \%$ homology of amino acid sequences and their role against drought stress was not reported in maize (Table 1). As a result of this search, nine genes were shortlisted with their orthologues present in maize genome.

Table 1. Short-listed genes chosen for the expression profiling

\begin{tabular}{c|c|c|c|c|c|c|c}
\hline \multirow{2}{*}{ S. No. } & \multirow{2}{*}{ Gene name } & \multirow{2}{*}{ Plant } & \multirow{2}{*}{ References } & \multirow{2}{*}{ Best hit in maize genome } & \multicolumn{3}{|c}{ Protein } \\
\cline { 6 - 9 } & & & & & & \\
\hline 1 & $R A B 18$ & Arabidopsis & Muller et al., 2012 & GRMZM5G83647_T05 & 93 & 85 & 83.5 \\
2 & SnRK2 & Arabidopsis & Zheng et al., 2010 & GRMZM2G155593_T01 & 84 & 86 & 80.9 \\
3 & GSNOR & Arabidopsis & Kwon et al., 2012 & GRMZM5G824600_T03 & 99 & 90.4 & 89.4 \\
4 & BADH15 & Sorghum & Wood et al., 1996 & GRMZM2G135470_T01 & 100 & 81 & 82.4 \\
5 & AtCBL1 & Arabidopsis & Kudla et al., 1999 & GRMZM2G107575_T01 & 100 & 77 & 77 \\
6 & OsCDPK7 & Rice & Saijo et al., 2000 & GRMZM2G314396_T01 & 100 & 89 & 89.6 \\
7 & OsNAC6 & Rice & Nakashima et al., 2007 & GRMZM2G014653_T01 & 81.5 & 80 & 83 \\
8 & AtNRGA1 & Arabidopsis & Li et al., 2014 & GRMZM2G003642_T01 & 90 & 77.5 & 70 \\
9 & OsTPS1 & Rice & Li et al., 2011 & GRMZM2G068943_T01 & 94 & 84 & 88 \\
\hline
\end{tabular}

\section{Total RNA isolation}

Collected leaves samples were immediately frozen in liquid nitrogen $\left(\mathrm{LN}_{2}\right)$. To extract RNA TRIzol method was used (Sambrook and Russel, 2001). After extraction it was resolved on TAE agarose gel of $1.2 \%$ concentration at $60 \mathrm{~V}$ for $45 \mathrm{~min}$. Then it was stained with Ethidium bromide and observed under UV light. It depicted a good quality of RNA with two distinct bands of $28 S$ and $18 S$ ribosomal RNA. The purity and concentration of RNA was calculated by mass spectrophotometry. Later, RNA samples were equilibrated by adding nucleases free water accordingly.

\section{Synthesis of $1^{\text {st }}$ strand of cDNA}

The mRNA preps were used for the synthesis of first strand of cDNA by using cDNA synthesis kit. To verify successful synthesis of cDNA, PCR was performed using primers 
of ZmActin, followed by gel electrophoresis. Moreover, the uniformity of bands for all the six drought stress treatments confirmed the synthesis of cDNA with equal concentration.

\section{Primer designing}

Primers were designed using available online tools justbio.com and primer3 (Table 2). Only exon regions of sequences were used to design primers. Every primer pair was specifically designed so that it should uniquely amplify the conserved region of the gene under investigation.

Table 2. Detail of the primers designed for the putative short-listed drought responsive genes

\begin{tabular}{|c|c|c|c|c|c|c|c|}
\hline S. No. & Gene name & Sequence & $\mathbf{L}$ & GC\% & $\mathbf{T m}$ & PS & References \\
\hline 1 & RAB18-F & GATTCCTCCTCCTCCTCGTC & 20 & 60 & 60 & \multirow{2}{*}{453} & \multirow{2}{*}{ Ayarpadikannan et al., 2014} \\
\hline 2 & RAB18-R & AGCAAATTCAATCCССТCCT & 20 & 45 & 58 & & \\
\hline 3 & SnRK2-F & CTGATTTGTGGCGTCAGCTA & 20 & 50 & 56 & \multirow{2}{*}{721} & \multirow{2}{*}{ Kulik et al., 2011} \\
\hline 4 & SnRK2-R & GGACTTGCTTCACCTGCTTC & 20 & 55 & 58 & & \\
\hline 5 & GSNOR-F & AAGTTTTGCAAGAGCGGAAA & 20 & 40 & 52 & \multirow{2}{*}{309} & \multirow{2}{*}{ Xu et al., 2013} \\
\hline 6 & GSNOR-R & TTCCAATGCACTCAAAGCTG & 20 & 45 & 54 & & \\
\hline 7 & BADH15-F & TAGGCCTACCACCAGGTGTC & 20 & 60 & 60 & \multirow{2}{*}{635} & \multirow{2}{*}{ Wood et al., 1996} \\
\hline 8 & BADH15-R & TGCAAGTTCCACAGCTTCAC & 20 & 50 & 56 & & \\
\hline 9 & AtCBL1-F- & GGCCTGATCAACAAGGAAGA & 20 & 50 & 56 & \multirow{2}{*}{226} & \multirow{2}{*}{ Kudla et al., 1999} \\
\hline 10 & AtCBL1-R & CAATAAACCCTGTGCCATCC & 20 & 50 & 56 & & \\
\hline 11 & OsCDPK7-F & CAAGAACGTCGTCGCTATCA & 20 & 50 & 56 & \multirow{2}{*}{428} & \multirow{2}{*}{ Wang et al., 2008} \\
\hline 12 & OsCDPK7--R & AAAATGGAGGCACACCACTC & 20 & 50 & 56 & & \\
\hline 13 & OsNAC6-F & TGGTGATGCACTACCTCTGC & 20 & 55 & 58 & \multirow{2}{*}{391} & \multirow{2}{*}{ Nakashima et al., 2007} \\
\hline 14 & OsNAC6-R & ACCCAGTCATCCAACCTGAG & 20 & 55 & 58 & & \\
\hline 15 & AtNRGA-F & CATGCACTGGACTCATTTGG & 20 & 50 & 56 & \multirow{2}{*}{168} & \multirow{2}{*}{ Li et al., 2014} \\
\hline 16 & AtNRGA-R & CTTCCAGTTGTGAAGCAGCA & 20 & 50 & 56 & & \\
\hline 17 & OsTPS1-F & TGTGAGGATGAGCGCACTAC & 20 & 55 & 58 & \multirow{2}{*}{416} & \multirow{2}{*}{ Kim et al., 2005} \\
\hline 18 & OsTPS1-R & ATTGCAGCACCCTTGGTAAC & 20 & 50 & 56 & & \\
\hline
\end{tabular}

\section{PCR for gene expression profiling}

PCR was performed using primer pairs specific for each candidate gene. PCR conditions were optimized. Initial denaturation temperature was $94{ }^{\circ} \mathrm{C}$ while the annealing temperatures were kept a few degrees lesser than the melting temperature $\left(\mathrm{T}_{\mathrm{m}}\right)$ of primers. Extension was performed at $72{ }^{\circ} \mathrm{C}$ for $30 \mathrm{~s}$. The final extension was performed at $72{ }^{\circ} \mathrm{C}$. The reaction products were separated by gel electrophoresis at $70 \mathrm{~V}$ for $45 \mathrm{~min}$.

\section{Tissue specific gene expression}

For Tissue-Specific gene expression similar procedure was repeated. Same size of pots i.e., $250 \mathrm{ml}$ was used, water was withheld for two days i.e., $48 \mathrm{~h}$ and then six drought stress treatments were given as $0 \mathrm{~h}, 6 \mathrm{~h}, 12 \mathrm{~h}, 24 \mathrm{~h}, 30 \mathrm{~h}$ and then $10 \mathrm{~h}$ after recovery irrigation. In this experiment, samples of stem and roots were collected from maize seedlings to investigate the gene expression in roots and stem other than leaves. Procedure of RNA isolation from samples, RNA equilibration, cDNA synthesis, primer designing and PCR was repeated for gene expression profiling in stem and roots. For quantifying the intensity of expressed genes, image $\mathbf{J}$ software was used. 


\section{Results}

\section{Gene expression profiling}

In genes expression study, two genes namely GSNOR of Arabidopsis (FDH1) with its maize orthologue GRMZM5G824600 and CDPK7 from rice with its maize orthologue GRMZM2G314396 were identified. However, seven genes RAB18, SnRK2, BADH15, AtCBL1, OsNAC6, AtNRGA1, OsTPS1 could not show their expression.

\section{GRMZM5G824600 - A maize orthologue for GSNOR}

The maize orthologue GRMZM5G824600 found as a result of BLAST on Maize GDB with its source gene AtGSNOR from Arabidopsis thaliana, expressed during the gene expression profiling. The gene showed a steady up regulation with increasing levels of drought stress (Fig. 1a). When two weeks old maize seedlings were subjected to water deficit conditions, AtGSNOR gene started showing its presence. At $0 \mathrm{~h}$, which was a control experiment, expression of the gene was at its minimum level and could be hardly detected. At $6 \mathrm{~h}$ the gene expression was observed easily. The drought stress was at its peak with successive increase of drought stress duration at $12 \mathrm{~h}, 24 \mathrm{~h}$ and finally at $30 \mathrm{~h}$. The gene showed a gradual increase with highest intensity at $30 \mathrm{~h}$. However, this gene showed a reverse trend in its expression intensity after $10 \mathrm{~h}$ of recovery irrigation.

\section{PCR for GRMZM2G314396 - A maize orthologue for OsCDPK7}

The gene selected from rice OsCDPK7 expressed itself as the maize orthologue, GRMZM2G314396 and showed its presence in maize genome. The gene displayed a certain expression pattern during the step wise exposure of the maize seedlings to drought stress conditions. The expression profiling provided evidence that it is functioning as drought responsive gene by showing up regulation from $0 \mathrm{~h}$ till $12 \mathrm{~h}$ of drought stress in maize genome. However, after $12 \mathrm{~h}$ of drought stress it showed a gradient of down regulation (Fig. 2a).

(A)
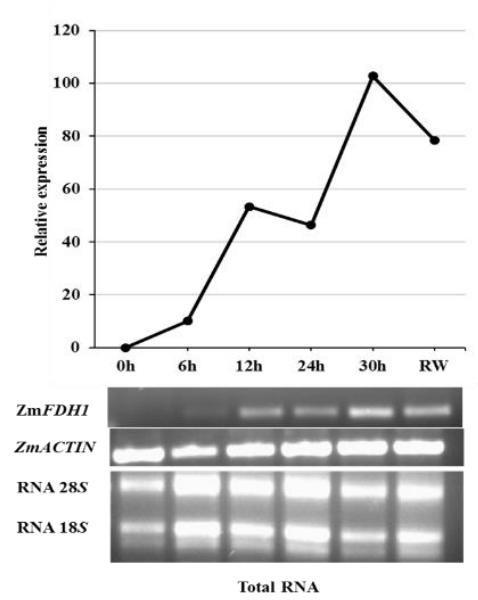

(B)

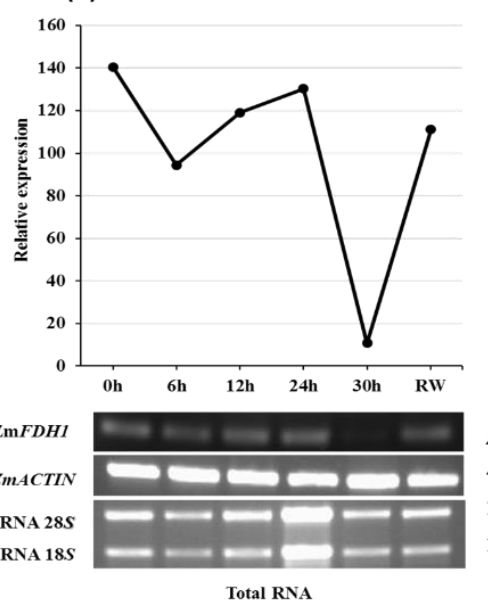

(C)

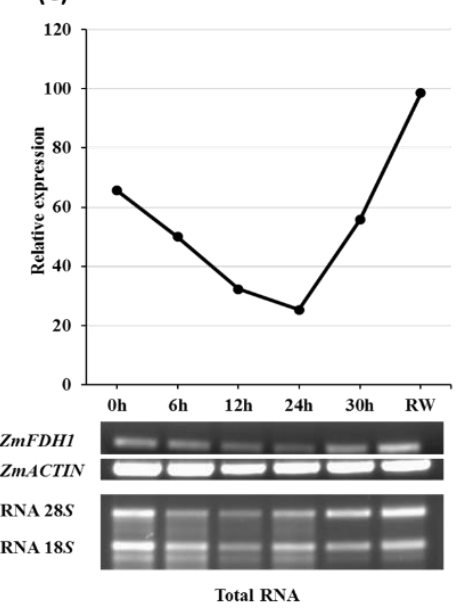

Figure 1. Expression pattern of GSNOR with size 309 bp upon exposure to drought stress. ZmActin is maize Actin gene loading control. Total RNA obtained shows ribosomal RNA bands of $28 S$ and $18 S$. The line graphs depict the gene expression pattern. (A) Gene expression profiling in leaves showing upregulation followed by down regulation at recovery irrigation.

(B) Expression profiling obtained in roots. (C) Gene expression pattern in stem 

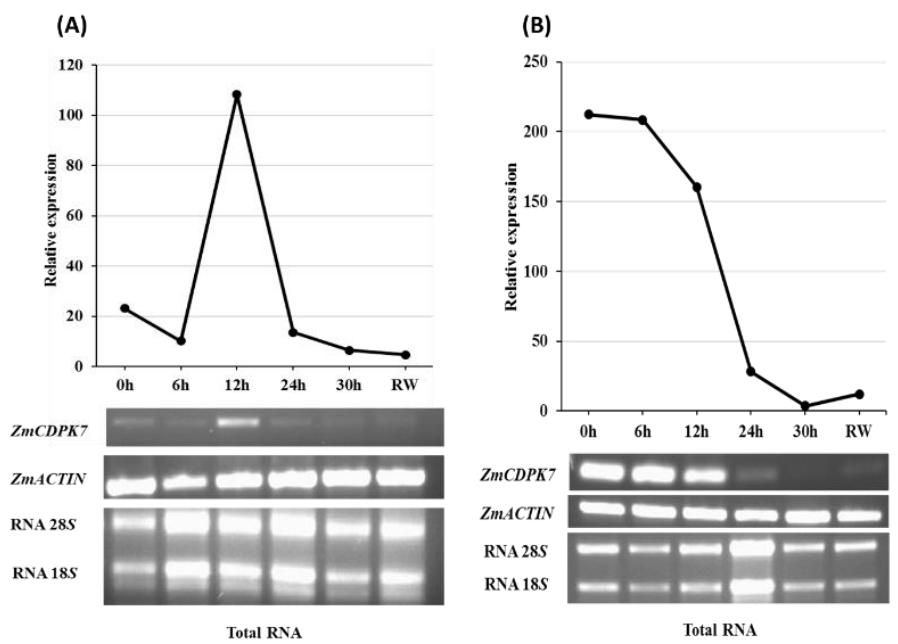

Figure 2. Expression profiling of CDPK7 with size 428 bp at various levels of drought stress. ZmActin is used as loading control. Total RNA obtained shows ribosomal RNA bands of $28 S$ and 18S. The line graphs display the gene expression patterns. (A) Gene expression profiling in leaves showing upregulation of the gene till $12 \mathrm{~h}$ followed by down regulation. (B) Expression profiling obtained in roots displaying an explicit pattern of down regulation

\section{GSNOR expression in tissues (roots and stem)}

In addition to leaves, gene expression was analyzed in roots and stem. On performing PCR for finding gene expression pattern of GSNOR in roots, it was observed that GSNOR displayed an overall declining pattern. Especially at $30 \mathrm{~h}$ of drought stress, expression of the gene was at its minimum level (Fig. 1b). The expression pattern in stem showed that the gene displayed a general trend of down regulation in first five treatments of drought stress, i.e., starting from $0 \mathrm{~h}$ till $30 \mathrm{~h}$ of exposure to water deficit conditions. GSNOR gene depicted an overall declining trend while on providing recovery irrigation it showed a sign of rejuvenation (Fig. lc).

\section{CDPK7 expression in tissues (roots and stem)}

In roots an obvious down regulated pattern for CDPK7 was observed (Fig. 2b). Initially its expression was found higher at $0 \mathrm{~h}$ and then it displayed a steady decline with subsequent increased levels of stress while at $30 \mathrm{~h}$ the gene expression almost vanished. However, after $10 \mathrm{~h}$ of recovery irrigation when $C D P K 7$ expression was checked it showed a sign of little reappearance. While expression of CDPK7 could not be detected in stem.

\section{Discussion}

GSNOR/FDH1 gene is induced by ABA and therefore it is included among the genes which follow ABA dependent pathway (Wang et al., 2015). ABA plays a very important role under abiotic conditions and more specifically under water deficit situations (Roychoudhury et al., 2013). Upon exposure to drought conditions, the expression of a drought responsive gene induced by $\mathrm{ABA}$ is quite logical. $\mathrm{ABA}$ accumulation in leaves makes the guard cells flaccid and results in closure of the stomata thus preventing loss of water through transpiration (Yamaguchi-Shinozaki and 
Shinozaki, 2006). Accumulation of ABA initiates Nitric Oxide (NO) signaling. When plants are exposed to various environmental stresses, NO plays its role as secondary messenger in transduction of signals against these stresses (Gill et al., 2013). Along with NO, the part played by S-nitrosoglutathione (GSNO) is equally important. GSNO is greatly important because it acts as internal reservoir for $\mathrm{NO}$ in cells and by possessing lesser molecular weight as compared to other biological molecules it acts as a carrier of NO (Leitner et al., 2009). Thus, GSNO performs S-nitrosylation of its target proteins and modify their functions. GSNO is associated with responses of plants against stress conditions (Chaki et al., 2009). The gene GSNOR catalyzes GSNO and modulates its level thus maintaining homeostatic environment in plants (Staab et al., 2008). GSNOR mutants showed thermotolerance defects, resistance to programmed cell death and diminished fertility (Chen et al., 2009). Such kinds of pleiotropic effects provide sufficient evidence that GSNOR participates not only in maintaining homeostatic environment, but it also takes part in responses against biotic as well as abiotic stress conditions (Xu et al., 2013). While considering the role of GSNOR, it is worthy to mention that it scavenges reactive oxygen species by controlling enzymes involved in anti-oxidation activity (Cheng et al., 2018).

In our experiment GSNOR/FDH1 depicted a steady up regulation in leaves thus proving its role under conditions of drought stress (Fig. 1a). Upon comparing the results displayed in Figure $1 a, b$ and $c$, it can be concluded that GSNOR gene was initially being expressed in roots. On gradual exposure of maize seedlings to drought stress, gene expression shifted from roots and stem towards leaves in order to modulate the consequences of consistently increasing drought stress. GSNOR is expressed constitutively in all tissues (Shi et al., 2014). In addition, as nitric oxide plays its role in root elongation and handling osmotic stress condition through accumulation of osmolytes, therefore its presence and expression in roots is understandable and can be justified (Leitner et al., 2009). GSNO, which is the substrate of the enzyme GSNOR, is the carrier and donor of NO (Malik et al., 2011). GSNO has lesser molecular weight as compared to other biological molecules (Corpas et al., 2013), therefore it is trans located through phloem to upper parts of the plant (Espunya et al., 2012) and while passing through stem, it eventually reaches to the leaves for donating NO. Analyzing the expression of GSNOR in leaves and roots shows that in case of roots the gene expression is minimum at $30 \mathrm{~h}$ while in contrast to this, in leaves its expression is at its peak. These results clearly indicate that due to the translocation of the substrate GSNO, the need for enzyme GSNOR gradually increased in leaves instead of roots and thus its expression displayed a gradual shift between tissues. The expression pattern in roots is almost opposite to the gene expression profile in leaves (Fig. la, b, c). Thus, it can be concluded that GSNOR shifted its expression from roots and stem towards leaves upon step wise exposure of the maize seedlings to drought conditions. The expression of GSNOR is closely associated with GSNO which is the substrate of the enzyme GSNOR. We can say that the activity of GSNOR enzyme is correlated with its substrate GSNO. When and where the GSNO concentration gets higher and seems to disrupt the homeostatic balance in cytosol, the GSNOR enzyme turns active and starts decomposing its substrate, hence the expression of GSNOR intensifies. The literature illustrates the significance of GSNO as carrier and donor of nitric oxide. Malik et al. (2011) reported that GSNO is trans located through phloem and it acts as a carrier of nitric oxide, trans locating it to the distant targets. It is necessary for signaling through mechanism of oxidation reduction reactions. It can be deduced that when concentration 
of GSNO was higher in a certain tissue the need for its catabolism into GSSG and GSH was also greater. Upon excessive accumulation of GSNO, the NADH-dependent enzyme S-nitrosoglutathione reductase (GSNOR) catabolizes and splits GSNO into oxidized glutathione (GSSG) and ammonia. As a result, GSNOR regulates and maintains the GSNO levels under biotic and abiotic stress conditions (Xu et al., 2013).

Due to abiotic stress conditions and more specifically under water deficit conditions, ABA concentration increases (Zhu, 2002). The rise in ABA enhances the levels of $\mathrm{Ca}^{2+}$ in cytosol (Kohler and Blatt, 2002). Whatever information are encoded in various stimuli, this information introduces an enhanced level of $\mathrm{Ca}^{2+}$ in cytosol and thus it determines the nature of response. This increase in calcium ions concentration is termed as calcium signatures (Evans et al., 2001). The elevation of $\mathrm{Ca}^{2+}$ ions is detected by a group of calcium sensors known as calcium responders for instance kinases which transmit the message downstream to their concerned targets (Reddy and Reddy, 2004). Similarly, Harmon et al. (2000) reported that calcium dependent protein kinases (CDPKs), sense, decode and ultimately translate the elevation of $\mathrm{Ca}^{2+}$ concentration into increased activity of proteins kinases and consecutive downstream signaling. When kinases e.g., CDPKs gets active they bring downstream events of phosphorylation of their target proteins and as a result enable the plant to cope against drought stress conditions. Phosphorylation of proteins is a reversible reaction which plays a significant role in stress signaling in eukaryotes. It is considered that protein phosphorylation regulates several basic cellular incidences ( $\mathrm{Xu}$ et al., 2009). Plentiful evidences disclosed that several biochemical reactions in plants are closely linked with phosphorylation of proteins (Shen et al., 2004). On induction of CDPKs the phosphorylation cascade is triggered and stress responsive genes or the transcription factors are targeted (Mahajan and Tuteja, 2005). Upon exposure of plants to various types of abiotic and biotic stresses for example drought, disease and saline environment, $\mathrm{Ca}^{2+}$ concentration is enhanced rapidly in cytoplasm of the cells (Hashimoto and Kudla, 2011). Thus various $\mathrm{Ca}^{2+}$ sensor proteins, sense and translate these $\mathrm{Ca}^{2+}$ signals into respective responses in the cells. The spatiotemporal changes in $\mathrm{Ca}^{2+}$ are regulated by sensor proteins (DeFalco et al., 2010). Kinases are an example of such kind of proteins. At first $\mathrm{Ca}^{2+}$ increase in cytosol. As a result, $\mathrm{Ca}^{2+}$ attach to elongation hand of calcium dependent protein kinase and as it is also obvious from its name that its functionality depends on attaching $\mathrm{Ca}^{2+}$ to its EF motif, hence upon activating, calcium dependent protein kinase starts performing phosphorylation of its target proteins.

Examining the expression pattern of CDPK7 in leaves (Fig. 2a), indicates that the gene upregulated up to $12 \mathrm{~h}$ but later on it displayed down regulation in successive treatments of drought stress. We can interpret from this obtained pattern that till $12 \mathrm{~h}$ of drought stress, the expression of the gene synthesized sufficient concentration of its product i.e., calcium dependent protein kinase. Therefore, in successive drought stress treatments of $24 \mathrm{~h}$ and $30 \mathrm{~h}$, the gene CDPK7 did not need to be expressed with same intensity and thus it got down regulated. The expression pattern depicted in Figure $2 a$ and $b$ suggests that $C D P K 7$ is involved in signaling mechanism. The signaling initiated in roots and then it gradually moved towards leaves. A comparison of CDPK7 expression between roots and leaves shows that in roots the gene is displaying a steady declining trend (Fig. $2 b$ ) while in leaves the gene up regulates up to $12 \mathrm{~h}$ followed be down regulation (Fig. 2a). This comparison indicates that CDPK7 initiated signaling from roots which gradually switched towards the aerial parts i.e., leaves. The higher expression of $C D P K 7$ in roots, at control conditions (i.e., $0 \mathrm{~h}$ ) suggests its involvement 
in root development and elongation of root hair cells (Ivashuta et al., 2005). With subsequent increased level of dehydration stress the expression apparently moved towards leaves. It can be deduced that the activity of kinases is required during stress conditions as they perform phosphorylation of their target proteins (Mahajan and Tuteja, 2005) and thus altering proteins activity, functioning and at times their cellular location. The overall net impact of this phosphorylation appears in the form of better survival of the plants which encounters osmotic stress conditions.

\section{Conclusions}

Drought is one of the major problems for agriculture in present as well as in near future. Developing drought tolerant varieties should be the integral part of a comprehensive plan to face this challenge. Therefore, identifying novel drought responsive genes and investigating their expression pattern was thought necessary and provided a motivation to conduct this research. Two genes namely GSNOR and CDPK7 were identified and their expression pattern was analyzed. It was deduced that these identified genes regulate certain important biochemical as well as physiological phenomena thus enabling maize plants to encounter drought stress. In future, a comprehensive screening program of various maize genotypes for drought tolerance is recommended through using gene expression profiling of drought responsive genes such as GSNOR and CDPK7. Altogether it is recommended to exploit the identified genes for developing drought resilience in maize crop through selection, hybridization and gene transformation.

Acknowledgements. This work is a part of PhD study. The author highly acknowledges Agriculture Department, Government of Balochistan for providing study leave and Department of Plant Breeding and Genetics, PMAS Arid Agriculture University Rawalpindi for facilitating this research work. The financial assistance to complete this research activity was granted by "Prime Minister's Fee Reimbursement Scheme for Less Developed Areas".

\section{REFERENCES}

[1] Alexandrov, N. N., Brover, V. V., Freidin, S., Troukhan, M. E., Tatarinova, T. V., Zhang, H., Swaller, T. J., Lu, Y., Bouck, J., Flavell, R. B., Feldmann, K. A. (2009): Insights into corn genes derived from large-scale cDNA sequencing. - Plant Molecular Biology 69(12): 179 .

[2] Ali, S., Liu, Y., Ishaq, M., Shah, T., Ilyas, A., Din, I. U. (2017): Climate change and its impact on the yield of major food crops: evidence from Pakistan. - Foods 6(6): 39.

[3] Asano, T., Hayashi, N., Kikuchi, S., Ohsugi, R. (2012): CDPK-mediated abiotic stress signaling. - Plant Signaling and Behavior 7(7): 817-821.

[4] Aslam, M., Maqbool, M. A., Zaman, Q. U., Latif, M., Ahmad, R. (2013): Responses of Mungbean genotypes to drought stress at early growth stages. - International Journal of Basic and Applied Sciences 13(5): 22-27.

[5] Ayarpadikannan, S., Chung, E., Kim, K., So, H. A., Schraufnagle, K. R., Lee, J. H. (2014): RsERF1 derived from wild radish (Raphanus sativus) confers salt stress tolerance in Arabidopsis. - Acta Physiologiae Plantarum 36(4): 993-1008.

[6] Battisti, D. S., Naylor, R. L. (2009): Historical warnings of future food insecurity with unprecedented seasonal heat. - Science 323(5911): 240-244. 
[7] Chaki, M., Valderrama, R., Fernández-Ocaña, A. M., Carreras, A., López-Jaramillo, J., Luque, F., Sanchez-Calvo, B. (2009): Protein targets of tyrosine nitration in sunflower (Helianthus annuus L.) hypocotyls. - Journal of Experimental Botany 60(15): 4221-4234.

[8] Chen, R., Sun, S., Wang, C., Li, Y., Liang, Y., An, F. (2009): The Arabidopsis paraquat resistant2 gene encodes an S-nitrosoglutathione reductase that is a key regulator of cell death. - Cell Research 19: 1377-1387.

[9] Chen, X., Gu, Z., Xin, D., Hao, L., Liu, C., Huang, J., Ma, B., Zhang, H. (2011): Identification and characterization of putative CIPK genes in maize. - Journal of Genetics and Genomics 38(2): 77-87.

[10] Cheng, T., Shi, J., Dong, Y., Ma, Y., Peng, Y., Hu, X., Chen, J. (2018): Hydrogen sulfide enhances poplar tolerance to high-temperature stress by increasing S-nitrosoglutathione reductase (GSNOR) activity and reducing reactive oxygen/nitrogen damage. - Plant Growth Regulation 4: 1-13.

[11] Cheong, Y. H., Pandey, G. K., Grant, J. J., Batistic, O., Li, L., Kim, B. G., Lee, S., Kudla, J., Luan, S. (2007): Two calcineurin B-like calcium sensors, interacting with protein kinase CIPK23, regulate leaf transpiration and root potassium uptake in Arabidopsis. The Plant Journal 52(2): 223-239.

[12] Corpas, F. J., Alché, J. d. D., Barroso, J. B. (2013): Current overview of Snitrosoglutathione (GSNO) in higher plants. - Frontiers in Plant Science 4: 126.

[13] Cortina, C., Culiáñez-Macia, F. A. (2005): Tomato abiotic stress enhanced tolerance by trehalose biosynthesis. - Plant Science 169(1): 75-82.

[14] D’Angelo, C., Weinl, S., Batistic, O., Pandey, G. K., Cheong, Y. H., Schültke, S., Albrecht, V., Ehlert, B., Schulz, B., Harter, K., Luan, S., Bock, R., Kudla, J. (2006): Alternative complex formation of the $\mathrm{Ca} 2+$ regulated protein kinase CIPK1 controls abscisic acid-dependent and independent stress responses in Arabidopsis. - The Plant Journal 48(6): 857-872.

[15] DeFalco, T. A., Bender, K. W., Snedden, W. A. (2010): Breaking the code: $\mathrm{Ca}^{2+}$ sensors in plant signalling. - Biochemical Journal 425(1): 27-40.

[16] Espunya, M. C., De Michele, R., Gómez-Cadenas, A., Martínez, M. C. (2012): SNitrosoglutathione is a component of wound-and salicylic acid-induced systemic responses in Arabidopsis thaliana. - Journal of Experimental Botany 63(8): 3219-3227.

[17] Evans, N. H., McAinsh, M. R., Hetherington, A. M. (2001): Calcium oscillations in higher plants. - Current Opinion in Plant Biology 4(5): 415-420.

[18] Gill, S. S., Hasanuzzaman, M., Nahar, K., Macovei, A., Tuteja, N. (2013): Importance of nitric oxide in cadmium stress tolerance in crop plants. - Plant Physiology and Biochemistry 63: 254-261.

[19] Greve, P., Kahil, T., Mochizuki, J., Schinko, T., Satoh, Y., Burek, P., G. Fischer, G., Tramberend, S., Burtscher, R., Langan, S., Wada, S. (2018): Global assessment of water challenges under uncertainty in water scarcity projections. - Nature Sustainability 1(9): 486-494.

[20] Harmon, A. C., Gribskov, M., Harper, J. F. (2000): CDPKs-a kinase for every Ca ${ }^{2+}$ signal? - Trends in Plant Science 5(4): 154-159.

[21] Hashimoto, K., Kudla, J. (2011): Calcium decoding mechanisms in plants. - Biochimie 93(12): 2054-2059.

[22] Ivashuta, S., Liu, J., Liu, J., Lohar, D. P., Haridas, S., Bucciarelli, B., Gantt, J. S. (2005): RNA interference identifies a calcium-dependent protein kinase involved in Medicago truncatula root development. - The Plant Cell 17(11): 2911-2921.

[23] Jaleel, C. A., Manivannan, P., Wahid, A., Farooq, M., Al-Juburi, H. J., Somasundaram, R., Panneerselvam, R. (2009): Drought stress in plants: a review on morphological characteristics and pigments composition. - International Journal of Agricultural Biology 11(1): 100-105.

[24] Jiao, J., Peluso, P., Shi, J., Liang, T., Stitzer, M. C., Wang, B., Campbell, M. S., Stein, J. C., Wei, X., Chin, C., Guill, K., Regulski, M., Kumari, S., Olson, A., Gent, J., Schneider, 
K. L., Wolfgruber, T. K. May, M. R., Springer, N. M., Antoniou, E., McCombie, W. R., Presting, G. G., McMullen, M., Ross-Ibarra, J., Dawe, R. K., Hastie, A., Rank, D. R., Ware, D. (2017): Improved maize reference genome with single-molecule technologies. Nature 546(7659): 524-527.

[25] Khoso, S., Wagan, F. H., Tunio, A. H., Ansari, A. A. (2015): An overview on emerging water scarcity in Pakistan, its causes, impacts and remedial measures. - Journal of Applied Engineering Science 13(1): 35-44.

[26] Kim, S. J., Jeong, D. H., An, G., Kim, S. R. (2005): Characterization of a droughtresponsive gene, OsTPS1, identified by the T-DNA gene-trap system in rice. - Journal of Plant Biology 48(4): 371-379.

[27] Kohler, B., Blatt, M. R. (2002): Protein phosphorylation activates the guard cell $\mathrm{Ca}^{2+}$ channel and is a prerequisite for gating by abscisic acid. - The Plant Journal 32(2): 185194.

[28] Kudla, J., Xu, Q., Harter, K., Gruissem, W., Luan, S. (1999): Genes for calcineurin B-like proteins in Arabidopsis are differentially regulated by stress signals. - Proceedings of the National Academy of Sciences 96(8): 4718-4723.

[29] Kulik, A., Wawer, I., Krzywińska, E., Bucholc, M., Dobrowolska, G. (2011): SnRK2 protein kinases-key regulators of plant response to abiotic stresses. - Omics: A Journal of Integrative Biology 15(12): 859-872.

[30] Kwon, E., Feechan, A., Yun, B. W., Hwang, B. H., Pallas, J. A., Kang, J. G., Loake, G. J. (2012): AtGSNOR1 function is required for multiple developmental programs in Arabidopsis. - Planta 236(3): 887-900.

[31] Langridge, P., Reynolds, M. P. (2015): Genomic tools to assist breeding for drought tolerance. - Current Opinion in Biotechnology 32: 130-135.

[32] Leitner, M., Vandelle, E., Gaupels, F., Bellin, D., Delledonne, M. (2009): NO signals in the haze: nitric oxide signalling in plant defence. - Current Opinion in Plant Biology 12(4): 451-458.

[33] Leterrier, M., Chaki, M., Airaki, M., Valderrama, R., Palma, J. M., Barroso, J. B., Corpas, F. J. (2011): Function of S-nitrosoglutathione reductase (GSNOR) in plant development and under biotic/abiotic stress. - Plant Signaling and Behavior 6(6): 789793.

[34] Li, H. W., Zang, B. S., Deng, X. W., Wang, X. P. (2011): Overexpression of the trehalose-6-phosphate synthase gene OsTPS1 enhances abiotic stress tolerance in rice. Planta 234(5): 1007-1018.

[35] Li, C. L., Wang, M., Ma, X. Y., Zhang, W. (2014): NRGA1, a putative mitochondrial pyruvate carrier, mediates $\mathrm{ABA}$ regulation of guard cell ion channels and drought stress responses in Arabidopsis. - Molecular Plant 7(10): 1508-1521.

[36] Liang, Y., Zhang, F., Wang, J., Joshi, T., Wang, Y., Xu, D. (2011): Prediction of droughtresistant genes in Arabidopsis thaliana using SVM-RFE. - Plos One 6(7): 21750.

[37] Luo, F., Deng, X., Liu, Y., Yan, Y. (2018): Identification of phosphorylation proteins in response to water deficit during wheat flag and grain development. - Botanical Studies 59(1): 28.

[38] Luo, L., Xia, H., Lu, B. R. (2019): Crop breeding for drought resistance. - Frontiers in Plant Science 10: 314.

[39] Mahajan, S., Sopory, S. K., Tuteja, N. (2006): Cloning and characterization of CBL-CIPK signalling components from a legume (Pisum sativum). - The FEBS Journal 273(5): 907-925.

[40] Mahajan, S., Tuteja, N. (2005): Cold, salinity and drought stresses: an overview. Biochemistry and Biophysiology 444: 139-158.

[41] Majeed, A., Muhammad, Z. (2019): Salinity: a major agricultural problem-causes, impacts on crop productivity and management strategies. - Plant Abiotic Stress Tolerance 3: 83-99. 
[42] Malik, S. I., Hussain, A., Yun, B. W., Spoel, S. H., Loake, G. J. (2011): GSNORmediated de-nitrosylation in the plant defence response. - Plant Science 181(5): 540-544.

[43] Mao, H., Wang, H., Liu, S., Li, Z., Yang, X., Yan, J., Jiansheng Li, J., Tran, L. P., Qin, F. (2015): A transposable element in a NAC gene is associated with drought tolerance in maize seedlings. - Nature Communications 6(1): 1-13.

[44] Marris, E. (2008): Water: more crop per drop. - Nature 452: 273-277.

[45] Mittal, S., Mallikarjuna, M. G., Rao, A. R., Jain, P. A., Dash, P. K., Thirunavukkarasu, N. (2017): Comparative analysis of CDPK family in maize, arabidopsis, rice and sorghum revealed potential targets for drought tolerance improvement. - Frontiers in Chemistry 5: 115 .

[46] Monneveux, P., Sanchez, C., Beck, D., Edmeades, G. (2006): Drought tolerance improvement in tropical maize source populations. - Crop Science 46(1): 180-191.

[47] Mugo, S., De Groote, H., Bergvinson, D., Mulaa, M., Songa, J., Gichuki, S. (2005): Developing Bt maize for resource-poor farmers - recent advances in the IRMA project. African Journal of Biotechnology 4(13): 19-30.

[48] Nakashima, K., Tran, L. S. P., Van Nguyen, D., Fujita, M., Maruyama, K., Todaka, D., Ito, Y., Hayashi, N., Shinozaki, K., Yamaguchi-Shinozaki, K. (2007): Functional analysis of a NAC-type transcription factor OsNAC6 involved in abiotic and biotic stress-responsive gene expression in rice. - The Plant Journal 51(4): 617-630.

[49] Nuccio, M. L., Wu, J., Mowers, R., Zhou, H. P., Meghji, M., Primavesi, L. F., Paul, M. J., Chen, X., Gao, Y., Haque, E., Basu, S. S., Lagrimini, L. M. (2015): Expression of trehalose-6-phosphate phosphatase in maize ears improves yield in well-watered and drought conditions. - Nature Biotechnology 33(8): 862-869.

[50] Pearson, W. R. (2013): An introduction to sequence similarity "homology" searching. Current Protocols in Bioinformatics 42(1): 1-3.

[51] Reddy, V. S., Reddy, A. S. (2004): Proteomics of calcium-signaling components in plants. - Phytochemistry 65(12): 1745-1776.

[52] Roychoudhury, A., Paul, S., Basu, S. (2013): Cross-talk between abscisic acid-dependent and abscisic acid-independent pathways during abiotic stress. - Plant Cell Reports 32(7): 985-1006.

[53] Rudd, J. J., Franklin-Tong, V. E. (2001): Unravelling response-specificity in $\mathrm{Ca}^{2+}$ signalling pathways in plant cells. - New Phytologist 151(1): 7-33.

[54] Saijo, Y., Hata, S., Kyozuka, J., Shimamoto, K., Izui, K. (2000): Over-expression of a single $\mathrm{Ca} 2+$-dependent protein kinase confers both cold and salt/drought tolerance on rice plants. - The Plant Journal 23(3): 319-327.

[55] Sambrook, J., Russel, D. W. (2001): Gel Retardation Assays for DNA Binding Proteins. Molecular Cloning: A Laboratory Manual. - Cold Spring Harbor Laboratory, Cold Spring, NY, pp. 13-17.

[56] Shen, Y. Y., Duan, C. Q., Liang, X. E., Zhang, D. P. (2004): Membrane-associated protein kinase activities in the developing mesocarp of grape berry. - Journal of Plant Physiology 161(1): 15-23.

[57] Shi, H., Ye, T., Zhu, J. K., Chan, Z. (2014): Constitutive production of nitric oxide leads to enhanced drought stress resistance and extensive transcriptional reprogramming in Arabidopsis. - Journal of Experimental Botany 65(15): 4119-4131.

[58] Staab, C. A., Alander, J., Brandt, M., Lengqvist, J., Morgenstern, R., Grafstrom, R. C., Hoog, J. O. (2008): Reduction of S-nitrosoglutathione by alcohol dehydrogenase 3 is facilitated by substrate alcohols via direct cofactor recycling and leads to GSH-controlled formation of glutathione transferase inhibitors. - Biochemical Journal 413(3): 493-504.

[59] Tuteja, N., Mahajan, S. (2007): Calcium signaling network in plants: an overview. - Plant Signaling and Behavior 2(2): 79-85.

[60] Wang, C. R., Yang, A. F., Yue, G. D., Gao, Q., Yin, H. Y., Zhang, J. R. (2008): Enhanced expression of phospholipase $\mathrm{C} 1$ (ZmPLC1) improves drought tolerance in transgenic maize. - Planta 227(5): 1127-1140. 
[61] Wang, P., Du. Y., Hou, Y., Zhao, Y., Hsu, C., Yuan, F., Zhu, X., Tao, W., Song, C., Zhu, J. (2015): Nitric oxide negatively regulates abscisic acid signaling in guard cells by Snitrosylation of OST1. - Proceedings of the National Academy Sciences of USA 112(2): 613-618.

[62] Wang, X., Zenda, T., Liu, S., Liu, G., Jin, H., Dai, L., Dong, A., Yang, Y., Duan, H. (2019): Comparative proteomics and physiological analyses reveal important maize filling-kernel drought-responsive genes and metabolic pathways. - International Journal of Molecular Sciences 20(15): 3743.

[63] Wood, A. J., Saneoka, H., Rhodes, D., Joly, R. J., Goldsbrough, P. B. (1996): Betaine aldehyde dehydrogenase in sorghum (molecular cloning and expression of two related genes). - Plant Physiology 110(4): 1301-1308.

[64] Xu, S., Ding, H., Su, F., Zhang, A., Jiang, M. (2009): Involvement of protein phosphorylation in water stress-induced antioxidant defense in maize leaves. - Journal of Integrative Plant Biology 51(7): 654-662.

[65] Xu, S., Guerra, D., Lee, U., Vierling, E. (2013): S-nitrosoglutathione reductases are lowcopy number, cysteine-rich proteins in plants that control multiple developmental and defense responses in Arabidopsis. - Frontiers in Plant Science 4: 430.

[66] Yamaguchi-Shinozaki, K., Shinozaki, K. (2006): Transcriptional regulatory networks in cellular responses and tolerance to dehydration and cold stresses. - Annual Review Plant Biology 57: 781-803.

[67] Yoshida, T., Fujita, Y., Sayama, H., Kidokoro, S., Maruyama, K., Mizoi, J., Shinozaki, K., Yamaguchi-Shinozaki, K. (2010): AREB1, AREB2, and ABF3 are master transcription factors that cooperatively regulate ABRE-dependent ABA signaling involved in drought stress tolerance and require $\mathrm{ABA}$ for full activation. - The Plant Journal 61(4): 672-685.

[68] Zheng, Z., Xu, X., Crosley, R. A., Greenwalt, S. A., Sun, Y., Blakeslee, B., Wang, L., Ni, W., Sopko, S. M., Yao, C., Yau, K., Burton, S., Zhuang, M., McCaskill, D. G., Gachotte, D., Thompson, M., Greene, T. W. (2010): The protein kinase SnRK2. 6 mediates the regulation of sucrose metabolism and plant growth in Arabidopsis. - Plant Physiology 153(1): 99-113.

[69] Zhu, J. K. (2002): Salt and drought stress signal transduction in plants. - Annual Review Plant Biology 53: 247-273. 